\title{
Perturbation of EGF-induced MAP kinase activation by TGF-B1
}

\section{C.E. Wenner} and S. Yan

\author{
Department of Biochemistry, Roswell Park Cancer Institute, \\ Buffalo, NY, USA
}

\section{Correspondence \\ C.E. Wenner \\ Department of Biochemistry \\ Elm and Carlton Sts. \\ Buffalo, NY 14263 \\ USA \\ Fax: + 1-716-845-8906 \\ E-mail: \\ wenner@sc3103.med.buffalo.edu \\ Presented at the I International Symposium on "Signal Transduction and Gene Expression in Cell Proliferation and Differentiation", São Paulo, SP, Brasil, \\ August 31-September 2, 1998.}

Received November 26, 1998 Accepted January 26, 1999

\section{Abstract}

TGF- $ß 1$ regulates both cellular growth and phenotypic plasticity important for maintaining a growth advantage and increased invasiveness in progressively malignant cells. Recent studies indicate that TGF- $\beta-1$ stimulates the conversion of epitheliod to fibroblastoid phenotype which presumably leads to the inactivation of growthinhibitory effects by TGF-ß1 (Portella et al. (1998) Cell Growth and Differentiation, 9: 393-404). Therefore, the investigation of TGF-ß1 signaling that leads to altered growth and migration may provide novel targets for the prevention of increased cell growth and invasion. Although much attention has been paid to TGF- $ß 1$ responses in epithelial cells, the above studies suggest that examination of signal transduction pathways in fibroblasts are important as well. Data from our laboratory are consistent with the concept that TGF- $\beta 1$ can act as a regulatory switch in density-dependent $\mathrm{C} 3 \mathrm{H} 10 \mathrm{~T} 1 / 2$ fibroblasts capable of either promoting or delaying G1 traverse. The regulation of this switch is proposed to occur prior to $\mathrm{pRb}$ phosphorylation, namely prior to activation of cyclin-dependent kinases. The current study is concerned with the evaluation of a key cyclin (cyclin D1) which activates cdk 4 and $\mathrm{p} 27^{\mathrm{KIP} 1}$ which in turn inhibit cdk 2 in the proliferative responses of epidermal growth factor (EGF) and platelet-derived growth factor (PDGF) and their modulation by TGF- $\beta 1$. Although the molecular events that lead to elevation of cyclin D1 are not completely understood, it appears likely that activation of p42/p44 involved in its transcriptional regulation. TGF- 31 delayed EGF- or PDGF-induced cyclin D1 expression and blocked the induction of active $\mathrm{p} 42 / \mathrm{p} 44^{\mathrm{MAPK}}$. The mechanism by which TGF- $\beta 1$ induces a block in $\mathrm{p} 42 / \mathrm{p} 44^{\mathrm{MAPK}}$ activation is being examined and the possibility that TGF- $\beta 1$ regulates phosphatase activity is being tested.
Key words

- Transforming growth factor

- MAP kinase

- Cyclin D1
Although there is much support for a negative regulatory role of TGF- $\beta$ in tumorigenesis, it is our view that TGF-ß1 not only provides a growth advantage in several types of progressively malignant epithelial cells but permits the development of a more invasive phenotype. This stems largely from observations by Balmain and colleagues and by others (cf. 1) that I) overexpression of TGF$\beta$-RII leads to an increased incidence of the highly invasive mouse skin spindle carcinoma (2) and II) expression of a dominantnegative TGFß-type II receptor in squamous cell clones prevents spontaneous conversion to the fibroblastoid type after subcutaneous injection in nude mice (1). These observa- 
tions support the idea that TGF- $\beta 1$ can act directly on keratinocytes in vivo to induce the reversible epithelial-mesenchymal conversion of a malignant metastatic keratinocyte cell line. There is also evidence that the responses to TGF- $\beta 1$ are markedly altered when well-differentiated tumor cells become progressively malignant, i.e., colon carcinoma cells switch their response to TGF- $\beta 1$ with tumor progression (3). In other words, metastatic colon carcinoma cells in primary culture respond to TGF- $\beta 1$ by proliferation, whereas the growth of moderate to welldifferentiated primary site colon carcinomas is inhibited by TGF- $\beta 1$ (4). Other recent studies have shown an association of TGF$B 1$ with increased malignancy in other tumor types (5). While TGF- $\beta 1$ inhibits normal mammary cell growth and morphogenesis in vivo (6), the increased abundance of TGF- $\beta 1$ protein in breast carcinoma is positively associated with disease progression as examined by immunocytochemistry using isotypespecific antisera $(7,8)$. Also, the metastatic potential of mammary adenocarcinoma cells was increased by TGF- $\beta 1$ (9) whereas the non-metastatic tumor cells were subject to growth inhibition. In a series of rat bladder carcinoma cell lines which were clonally derived, the expression of TGF-B1 mRNA increased in conjunction with the biological aggressiveness of the cell lines (10). Thus, in both human tumors and in experimental model systems, TGF- $\beta 1$ is associated with increased disease progression in epidermal, colon, breast, and bladder cancer. Studies by Friedman and colleagues (3) reported that the in vivo mixture of TGF- $\beta 1$ growth-inhibited and of TGF- $\beta 1$ growth-stimulated tumor cells found in the primary tumor were replicated using cell lines derived from the same tumor, and provide a basis for the growth advantage possessed by the more invasive cells.

Oft et al. (11) reported that normal and Ras-transformed mammary epithelial cells grown in collagen gels maintain their epithe- lial characteristics. However, treatment with TGF- $\beta 1$ of normal cells results in growth arrest but the same treatment of Ras-transformed epithelial cells causes them to become fibroblastoid, invasive, and resistant to growth inhibition by TGF- $\beta 1$. Thus, metastasis of epithelial tumor cells can be associated with the acquisition of fibroblastoid features.

These studies suggest that the examination of signal transduction pathways in a mesenchymal cell line is of inherent value as is the study of negative effects of TGF- $\beta 1$. The study of TGF- $\beta 1$ in a cell line such as $\mathrm{C} 3 \mathrm{H} 10 \mathrm{~T} 1 / 2$ mouse embryonic fibroblasts is useful in that these cells provide ease of synchronization to obtain a relatively homogeneous cell population with which to follow cell cycle stimulation by TGF- $\beta 1$ and its interaction with signal transduction pathways initiated by other mitogens.

We and others have observed that TGF$\beta 1$ can act as a regulatory switch by delaying epidermal growth factor (EGF) or plateletderived growth factor (PDGF)-induced DNA synthesis $(12,13)$. It was, therefore, of interest to examine the mechanism by which TGF- $\beta 1$ elicits these responses. The key factors involved in G1-S checkpoint control have recently been elucidated. That is, cell cycle progression is dependent on G1 cdk activity which is regulated by two counterregulatory protein types, i.e., cyclins, the positive effectors and cdk inhibitors (cdkis), the negative effectors. Cyclin D1 and p27 are important representatives of each type, respectively. In $\mathrm{C} 3 \mathrm{H}$ 10T1/2 cells, EGF stimulates cell growth by up-regulating cyclin D1 whereas TGF- $\beta 1$ stimulates DNA synthesis by down-regulating $\mathrm{p} 27^{\mathrm{KIP} 1}(13,14)$. Despite the independent mechanisms by which each ligand stimulated DNA synthesis, when both ligands were present, there was a delay in the kinetics as observed when EGF was added alone. This led us to compare the levels of cyclin D1 and p27 ${ }^{\mathrm{KIP} 1}$ under these conditions. We found that al- 
though $\mathrm{p} 27^{\mathrm{KIP} 1}$ was unchanged when both ligands were present, TGF- $\beta 1$ prevented the up-regulation of EGF-induced cyclin D1 levels (14). It was, therefore, of interest to examine the effects of TGF- $\beta 1$ on pathways contributing to EGF-induced cyclin D1 expression.

Evidence for the involvement of the MEK-MAPK (MAPK = mitogen-activated protein kinase; MEK = MAPK kinase) pathway in cyclin D1 expression has been presented (15). MAPKs augment the activity of several transcription factors including the activator protein-1 complex (AP-1, c-Fos/cJun), ATF-2, and members of the ETS transcription factor family. The donation of PD 098059, a specific inhibitor of the activation of mitogen-activated protein kinase in vitro and in vivo, by Dr. Alan R. Saltiel, Parke Davis Research Division, Warner Lambert Company, Ann Arbor, MI, has allowed us to carry out initial studies to examine its effect on EGF-induced DNA synthesis in $\mathrm{C} 3 \mathrm{H}$ 10T1/2 cells as described below.

As seen in Figure 1, PD $098059(50 \mu \mathrm{M})$ inhibited EGF-induced DNA synthesis. In contrast, preliminary studies with PD 098059 $(10 \mu \mathrm{M})$ indicate that although a less pronounced inhibition of EGF-induced DNA synthesis was observed, there was no effect of PD 098059 on TGF-B1 induced DNA synthesis. Thus, these findings are consistent with the possibility that MAP kinase is required for activation of cyclin D1 synthesis by EGF but that it may not be critical for TGF- $\beta 1$-induced DNA synthesis. We therefore carried out studies to determine its effect on EGF-induced MAPK activation.

With the use of an anti-active $\mathrm{p} 42 / \mathrm{p} 44^{\mathrm{MAPK}}$ antibody from Promega Corp. (Madison, WI, USA), we examined the effect of TGF- $\beta 1$ on the activation of $\mathrm{p} 42 / \mathrm{p} 44^{\mathrm{MAPK}}$. EGF induces marked stimulation of $\mathrm{p} 42 / \mathrm{p} 44^{\mathrm{MAPK}}$ activity within minutes and significant enhancement at $10 \mathrm{~min}$ post-treatment as does tetradecanoyl-phorbol acetate (TPA). It was also observed that TGF- $ß 1$ significantly reduced
EGF-induced p42/p44MAPK activation minutes after both factors were applied at the same time (Figure 2). In view of previous studies indicating a requirement of $\mathrm{p} 42 /$ p44 ${ }^{\mathrm{MAPK}}$ activation for cyclin D1 synthesis, our findings are consistent with the possibility that TGF- $\beta 1$ inhibits $\mathrm{p} 42 / \mathrm{p} 44^{\mathrm{MAPK}}$ activity, which conceivably prevents EGF-induced cyclin D1 activity.

We also were able to evaluate the contribution of the MAPK pathway to the induction of cyclin D1 and p27KIP1 down-regulation with the use of a ligand, namely, the phorbol ester TPA, which induced proliferative responses by both mechanisms (16). It was observed in this study that with postconfluent, quiescent fibroblasts, TPA $\left(10^{-7}\right)$ induced down-regulation of $\mathrm{p} 27^{\mathrm{KIP} 1}$ and upregulation of cyclin D1 as early as within $5 \mathrm{~h}$.

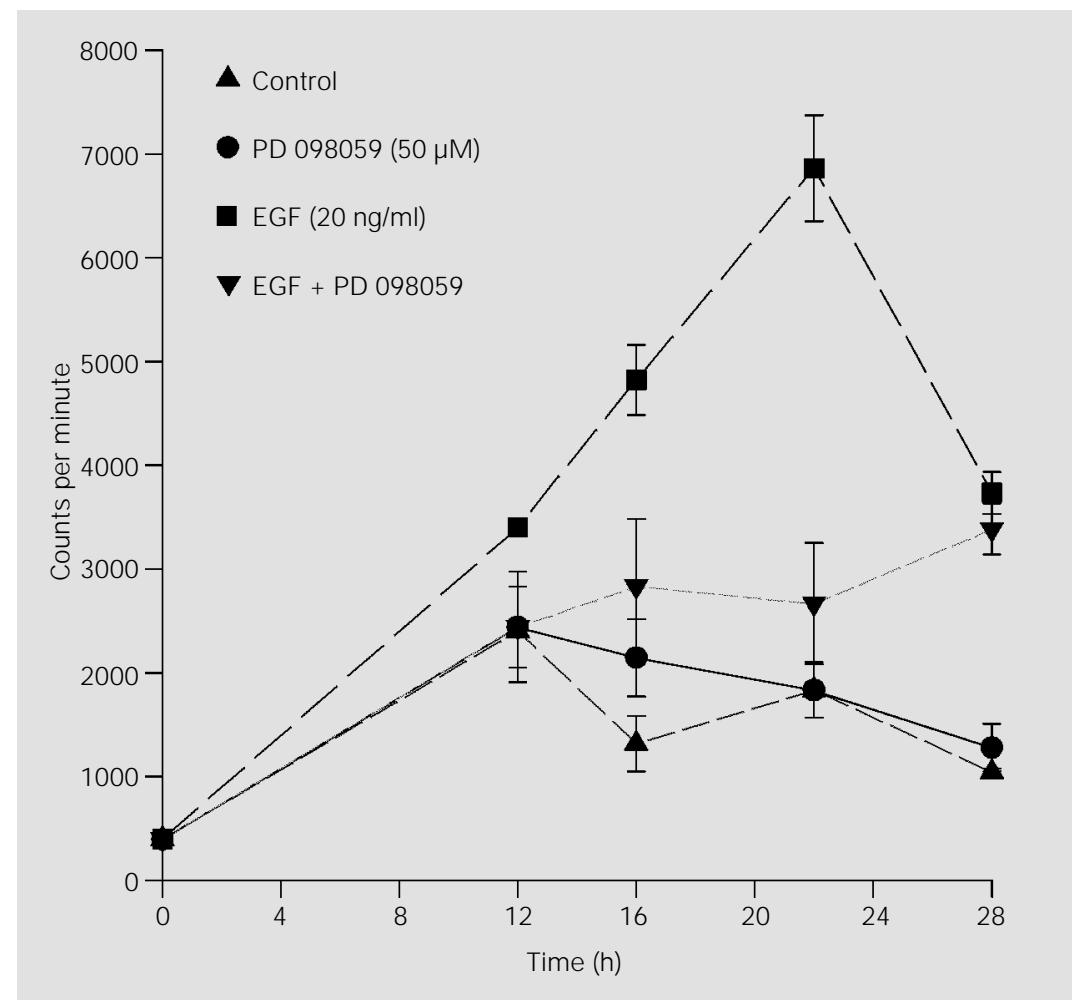

Figure 1 - Effect of PD 098059 on epidermal growth factor (EGF)-induced DNA synthesis. Postconfluent, quiescent C3H 10T1/2 cells were switched to Dulbecco's modified Eagle's medium (DMEM) containing $0.1 \%$ fetal bovine serum (FBS) $24 \mathrm{~h}$ prior to $\mathrm{T}=0 \mathrm{~h}$ when 50 $\mu \mathrm{M}$ PD 098059 or $20 \mathrm{ng} / \mathrm{ml}$ EGF was added. DNA synthesis was measured by 2 -h pulse $\left[{ }^{3} \mathrm{H}\right]$-thymidine incorporation at the indicated times. 


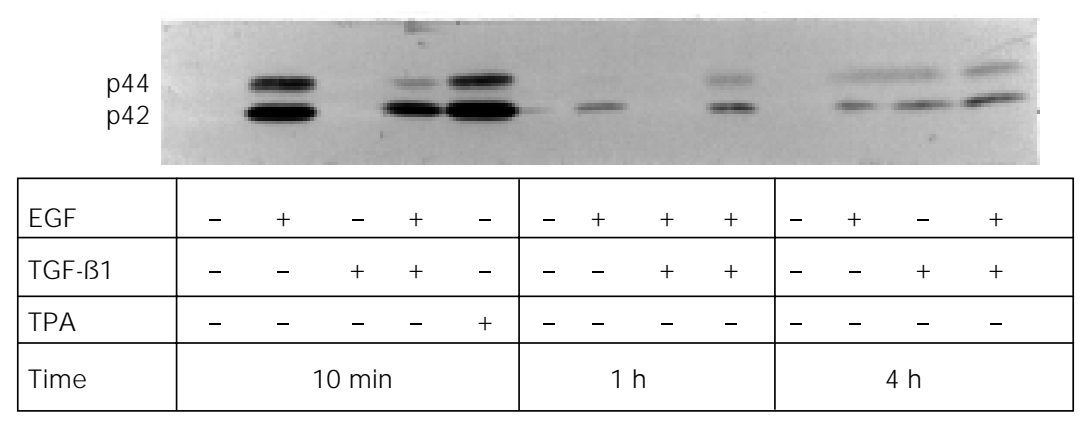

Figure 2 - Effect of TGF-B1 on epidermal growth factor (EGF)-induced p42/p44MAPK activation. Postconfluent, quiescent $\mathrm{C} 3 \mathrm{H}$ 10T1/2 cells were switched to DMEM containing $0.1 \%$ FBS $24 \mathrm{~h}$ prior to $\mathrm{T}=0 \mathrm{~h}$ when $20 \mathrm{ng} / \mathrm{ml}$ EGF or $5 \mathrm{ng} / \mathrm{ml}$ TGF-ß1 or $1 \mu \mathrm{M}$ tetradecanoylphorbol acetate (TPA) was added. At the indicated times, whole cell extracts were prepared, subjected to SDS-PAGE on $12 \%$ gels, and transferred to nitrocellulose (14). Western blotting analysis was performed by probing the blots with a polyclonal antibody to the active, dually phosphorylated p42/p44MAPK obtained from Promega Corp.

The up-regulation of cyclin D1 but not the down-regulation of $\mathrm{p} 27^{\mathrm{KIP} 1}$ was sensitive to PD $098059(10 \mu \mathrm{M})$. This was also correlated with the inhibition of PD 098059 on TPA-induced $\mathrm{p} 42 / \mathrm{p} 44^{\mathrm{MAPK}}$ as well as DNA synthesis as observed by $\left[{ }^{3} \mathrm{H}\right]$-thymidine incorporation. These studies agree with the findings of Weber et al. (17) who reported that overexpression of a dominant negative extracellular regulated kinase (ERK) resulted in the inhibition of PDGF-induced cyclin D1 expression but had no effect on PDGF-induced $\mathrm{p} 27^{\mathrm{KIP} 1}$ degradation. In summary, these findings suggest that activation of the cell cycle by TPA as well as by EGF and PDGF involves the induction of $\mathrm{p} 42 / \mathrm{p} 44^{\mathrm{MAPK}}$ activity followed by activation of the cyclin D1 promoter. Further, the data suggest that there is an independent regulation of cyclin D1 and $\mathrm{p} 27^{\mathrm{KIP} 1}$ and the convergence of the $\mathrm{p} 42 /$ p44 MAPK pathway leading to cyclin D1 activation with another pathway responsible for $\mathrm{p} 27^{\mathrm{KIPl}}$ down-regulation establishes the activation state of complexes of cyclin-dependent kinases following mitogen treatment.

Since a dynamic balance exists between phosphorylation and dephosphorylation in the MAPK pathway resulting from an interplay between protein kinases and phosphatases, modification of either component is likely to have an important impact on signal transduction. Therefore, it is considered that since activation of $\mathrm{p} 42 / \mathrm{p} 44^{\mathrm{MAPK}}$ requires dual phosphorylation on Thr and Tyr residues by MEK $1 / 2$, the protein phosphatases that inactivate MAPKs and MEKs must play critical roles in the level of activation of these enzymes in vivo but their identities are not clear. The catalytic subunit of protein phosphatase-1 (PP1) and protein phosphatase-2A (PP2A) inactivates MEK in vitro, with $\mathrm{PP} 2 \mathrm{~A}$ being much more effective (18). Also, a dual specificity MAP kinase phosphatase was found by the Tonks group to be highly specific for MAP kinase in vitro (19). Further studies are needed to learn whether TGF- $\beta 1$ influences phosphatase activity which blocks EGF-induced p42/ p44 ${ }^{\mathrm{MAPK}}$ activity.

\section{References}

1. Portella G, Cumming SA, Liddell J , Cui W, Ireland H, Akhurst RJ \& Balmain A (1998). Transforming growth factor $B$ is essential for spindle cell conversion of mouse skin carcinoma in vivo: Implications for tumor invasion. Cell Growth and Differentiation, 9: 393-404.

2. Cui W, Fowlis DJ, Bryson S, Duffie E, Ireland H, Balmain A \& Akhurst RJ (1996). TGFß1 inhibits the formation of benign skin tumours but enhances progression to invasive spindle cell carcinomas in transgenic mice. Cell, 86: 531-542.

3. Hsu S, Huang F, Hafez M, Winawer $\mathrm{S} \&$
Friedman E (1994). Colon carcinoma cells switch their response to transforming growth factorß1 with tumor progression. Cell Growth and Differentiation, 5: 267275.

4. Schroy P, Rifkin J, Coffey RJ , Winawer S \& Friedman E (1990). Role of TGF-ß1 in induction of colon carcinoma differentiation by hexamethylene bisacetamide. Cancer Research, 50: 261-265.

5. Arrick BA, Lopez AR, Elfman F, Ebner R, Damsky CH \& Derynck R (1992). Altered metabolic and adhesive properties and increased tumorigenesis associated with in- creased expression of transforming growth factor beta. J ournal of Cell Biology, 118: 715-726.

6. Silberstein GB \& Daniel CW (1987). Reversible inhibition of mammary gland tumor growth by TGFß. Science, 237: 291293.

7. Gorsch SM, Memoli VA, Stukel TA, Gold LI \& Arrick BA (1992). Immunohistochemical staining for transforming growth factor beta 1 associates with disease progression in human breast cancer. Cancer Research, 52: 6949-6952.

8. Pelton RW, Saxena B, J ones M, Moses 
HL \& Gold LI (1991). Immunohistochemical localization of TGF beta 1, TGF beta 2, and TGF beta 3 in the mouse embryo: expression patterns suggest multiple roles during embryonic development. J ournal of Cell Biology, 115: 1091-1105.

9. Welch DR, Fabra A \& Nakajima M (1990). Transforming growth factor beta stimulates mammary adenocarcinoma cell invasion and metastatic potential. Proceedings of the National Academy of Sciences, USA, 87: 7678-7682.

10. Kawamata H, Azuma M, Kameyama S, Nan L \& Oyasu R (1992). Effect of epidermal growth factor/transforming growth factor alpha and transforming growth factor beta 1 on growth in vitro of rat urinary bladder carcinoma cells. Cell Growth and Differentiation, 3: 819-825.

11. Oft M, Peli J, Rudaz C, Schwarz H, Beug $\mathrm{H} \&$ Reichmann E (1996). TGF-ß1 and HaRas collaborate in modulating the phenotype plasticity and invasiveness of epithelial tumor cells. Genes and Development, 10: 2462-2477.
12. Kim TA, Cutry $A F$, Kinniburgh AJ \& Wenner CE (1993). Transforming growth factor beta 1-induced delay of cell cycle progression and its association with growth-related gene expression in mouse fibroblasts. Cancer Letters, 71: 125-132.

13. Ravitz MJ \& Wenner CE (1977). Cyclindependent kinase regulation during $\mathrm{Gl}$ phase and cell cycle regulation by TGFbeta. Review, Academic Press Advances in Cancer Research, 71: 165-207.

14. Ravitz MJ , Yan S, Dolce C, Kinniburgh AJ $\&$ Wenner CE (1996). Differential regulation of p27 and cyclin D1 by TGF-beta and EGF in C3H 10T1/2 mouse fibroblasts. J ournal of Cellular Physiology, 168: 510520.

15. Albanese $\mathrm{C}$, J ohnson J, Watanabe $\mathrm{G}$, Eklund N, Vu D, Arnold A \& Pestell RG (1995). Transforming p21ras mutants and c-Ets-2 activate the cyclin D1 promoter through distinguishable regions. J ournal of Biological Chemistry, 270: 2358923597.

16. Yan S \& Wenner CE (1998). Cyclin D1 and
p27KIP1 as key cell cycle regulators in growth factor-induced cell proliferation. Proceedings of the 17th International Cancer Congress, Rio de J aneiro, RJ , Brazil. Monduzzi Editore, Bologna, Italy (in press).

17. Weber J D, Hu W, J efcoat J r SC, Raben DM \& Baldassare J J (1997). Ras-stimulated extracellular signal-related kinase 1 and RhoA activities coordinate platelet-derived growth factor-induced G1 progression through the independent regulation of cyclin D1 and p27. J ournal of Biological Chemistry, 272: 32966-32971.

18. Alessi DR, Gomez N, Moorhead G, Lewis T, Keyse SM \& Cohen P (1995). Inactivation of p42 MAP kinase by protein phosphatase $2 \mathrm{~A}$ and a protein tyrosine phosphatase, but not CL100, in various cell lines. Current Biology, 5: 283-295.

19. Sun $\mathrm{H}$, Charles $\mathrm{CH}$, Lau LF \& Tonks NK (1993). MKP-1 (3CH134), an immediate early gene product, is a dual specificity phosphatase that dephosphorylates MAP kinase in vivo. Cell, 75: 487-493. 